\title{
Enzimas carboidrases na dieta de porcas lactantes e suas leitegadas
}

\author{
Carbohydrase enzymes in diets for lactating sows and their litters
}

\author{
Débora Cristina Nichelle Lopes ${ }^{\mathrm{I}^{*}}$ Gustavo Julio Mello Monteiro de Lima ${ }^{\mathrm{II}}$ \\ Eduardo Gonçalves Xavier ${ }^{\mathrm{I}}$ Rogério Barancelli ${ }^{\mathrm{II}}$ João Alberto Lauxen ${ }^{\text {IV }}$ \\ Berilo de Souza Brum Júnior ${ }^{I}$ Beatriz Simões Valente ${ }^{I}$
}

\section{RESUMO}

O experimento foi realizado para se avaliar o uso de um complexo enzimático (CE) contendo carboidrases na dieta de porcas lactantes e de suas leitegadas. Foram utilizadas 264 fêmeas cruzadas geneticamente homogêneas, que foram bloqueadas pela ordem de parto e distribuídas ao acaso em quatro tratamentos, resultantes de um arranjo fatorial $2 \times 2$ (dieta lactação $(D L)$ x dieta pré-inicial (DPI)), com dois níveis cada fator (com e sem CE). Nas porcas, foram avaliados: peso ao desmame (PDESM); variação do peso corporal; espessura de toucinho (ET); variação de ET; escore corporal (EC); consumo de ração (CRF) e composição do leite e nas leitegadas: consumo de ração (CRL); peso da leitegada ao nascer e ao desmame (PLDESM); e peso médio do leitão ao desmame (PMLDESM). Não houve interação significativa entre $D L e$ DPI para nenhuma variável resposta. O PDESM, a ET, a variação de ET, o EC e a composição do leite (teores de gordura, proteína bruta, lactose e matéria seca) das porcas não foram influenciados $(P>0,10)$ pela adição de enzimas na $D L$ e na DPI. O CRF e o CRL não foram influenciados $(P>0,10)$ pelos tratamentos. O PLDESM e o PLMDESM foram significativamente maiores quando as porcas receberam DL suplementada com $C E$, em comparação àquelas que não receberam CE na dieta (74,6 vs 72,9kg e 6,32 vs 6,47kg, respectivamente). Houve um aumento de $1,7 \mathrm{~kg}$ no PLDESM e de $0,15 \mathrm{~kg}$ no PLMDESM ( $P=0,06$ e $P=0,07$, respectivamente), resultando em um incremento estimado de $2,27 \mathrm{~kg}$ de peso vivo quando os animais chegam ao peso de abate. Porcas alimentadas com rações suplementadas com complexo enzimático contendo carboidrases apresentam leitegadas mais pesadas ao desmame.

Palavras-chave: suplementação enzimática, leitões, nutrição animal, matriz suína, suínos.

\section{ABSTRACT}

This research was conducted to evaluate the effect of adding enzymatic complex (EC) containing carbohydrases to diets for lactating sows and their litters. A total of 264 genetically homogeneous crossbred sows were used. They were blocked by farrowing order and randomly allotted to four treatments, in a $2 \times 2$ factorial arrangement (lactating diet (LD) $x$ pre-starter diet (PD)), with two levels per factor (with or without EC). The following variables were measured in the sows: weaning weight; weaning weight variation; backfat; backfat variation; body condition; feed consumption and milk composition. The following variables were measured in the litter: feed consumption; post-natal weight; weaning weight; and average weaning weight. No interaction was found among $L D$ and PD for any of the variables studied. Additionally, no effect was observed for either, female weight, backfat, body condition score or milk composition (fat content, crude protein, lactose and dry matter). Litter weaning weight and average litter weaning weight were higher when LD was supplemented with EC in comparison to the piglets from sows fed with diets without EC (74.6 vs $72.9 \mathrm{~kg}$ and 6.32 vs $6.47 \mathrm{~kg}$, respectively). Litters from female fed with CE were $1.7 \mathrm{~kg}$ heavier at weaning and showed a $0.15 \mathrm{~kg}$ increase in the average weaning weight $(P=0.06 ; P=0.07$, respectively). This resulted in an estimate $2.27 \mathrm{~kg}$ increase in the body weight at slaughter. Lactating sows fed with diets containing enzymatic complex with carbohydrases had heavier litters at weaning.

Key words: enzyme supplementation, piglets, animal nutrition, sow, swine.

IDepartamento de Zootecnia, Universidade Federal de Pelotas (UFPEL), Campus universitário, s/n, 96010-900, Pelotas, RS, Brasil. E-mail: dcn_lopes@yahoo.com.br. Autor para correspondência.

IEEmpresa Brasileira de Pesquisa Agropecuária (EMBRAPA Suínos e Aves), Concórdia, SC, Brasil.

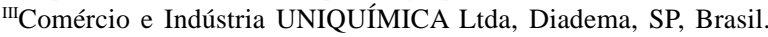

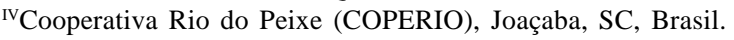




\section{INTRODUÇÃO}

$\mathrm{Na}$ suinocultura, o aumento da produtividade está relacionado com a eficiência no desempenho reprodutivo das porcas, que, na prática, é avaliada pelo número de leitões produzidos/fêmea/ ano. Amaximização desse índice produtivo implica maior desgaste corporal da fêmea durante o período de desenvolvimento fetal, na gestação e também durante a lactação, quando há necessidade de aumento na produção de leite para garantir a sobrevivência dos leitões.

O desempenho produtivo e reprodutivo da fêmea suína está relacionado a sua condição corporal durante a lactação, a qual depende diretamente do consumo de ração, que geralmente é limitado nessa fase (DE SOUZA, 2003). Para maximizar o desempenho reprodutivo das fêmeas suínas altamente prolíferas, tem-se procurado desenvolver e implantar estratégias nutricionais e alimentares nas fases de gestação e lactação, para reduzir a perda da condição corporal durante ciclos reprodutivos subsequentes. Dentre essas estratégias, está o uso de enzimas exógenas nas dietas de fêmeas suínas gestantes e lactantes (KIM, 2002; DE SOUZA, 2003).

A soja e outras leguminosas contêm polissacarídeos não amiláceos (PNAs), oligossacarídeos (rafinose, estaquiose e verbascose), fitato, além de outros fatores antinutricionais que levam a problemas digestivos, reduzindo o desempenho animal, podendo resultar em problemas ambientais pelo aumento da excreção dos nutrientes que se encontram na forma indisponível para o animal (PENZ JR., 1998; XAVIER, 2003; XAVIER et al., 2005). A digestão dos alimentos pelos animais é feita por enzimas produzidas pelo próprio animal e pelos micro-organismos presentes no trato digestório. Porém, o processo de digestão em não ruminantes não é eficiente (SHEPPY, 2001) e, mesmo com o avanço da idade e com a exposição aos substratos específicos, esses animais não possuem a capacidade de produzir e secretar enzimas endógenas para digerir os PNAs (PENZ JR., 1998).

O uso de enzimas exógenas em dietas convencionais de suínos (à base de milho e farelo de soja) aumenta a digestibilidade dos nutrientes e o desempenho dos animais (KIM, 2002; DE SOUZA, 2003; KIM et al., 2006). A adição de enzimas nas dietas pré-iniciais dos leitões lactentes é uma prática aconselhável devido, principalmente, à deficiência enzimática endógena desses animais (XAVIER et al., 2005).

No entanto, há poucas pesquisas realizadas avaliando-se a adição de enzimas exógenas na dieta de fêmeas suínas lactantes, bem como na de suas leitegadas. Desse modo, este estudo foi realizado com o objetivo de avaliar os efeitos da suplementação de dieta de fêmeas suínas lactantes e de suas leitegadas com um CE contendo carboidrases ( $\alpha$-galactosidase, galactomananase, xilanase e $\beta$-glucanase) sobre o desempenho produtivo desses animais.

\section{MATERIAL E MÉTODOS}

O experimento foi realizado em uma granja comercial localizada no Estado de Santa Catarina, entre agosto e dezembro de 2006. Foram utilizadas 264 fêmeas suínas de uma linhagem comercial (Landrace x Large White), de ordens de parto de um a seis, e suas leitegadas. As matrizes foram transferidas para a maternidade aos 107 dias de gestação, semanalmente, sendo então alojadas em celas parideiras. As salas não eram climatizadas, e o controle da ventilação do ambiente foi realizado através do manejo de cortinas laterais.

Foram utilizados quatro tratamentos, correspondentes às combinações de um arranjo fatorial 2 x 2 (Dieta lactação (DL) com e sem CE x Dieta préinicial (DPI) com e sem CE), em que: T1 - DL sem CE + DPI sem CE; T2 - DL sem CE + DPI com CE; T3 - DL com CE + DPI sem CE; T4 - DL com CE + DPI com CE. As rações foram fornecidas ad libitum, sendo a DL fornecida para as fêmeas a partir do parto e a DPI fornecida aos leitões a partir do quinto dia de vida. Durante o intervalo desmame-cio, as fêmeas foram alimentadas com a DL, três vezes ao dia, totalizando $4,5 \mathrm{~kg}$ de ração (1,5kg/refeição). A DL e a DPI foram formuladas para atender às exigências nutricionais dos suínos em cada fase estudada (Tabelas 1 e 2). Foi utilizado neste experimento um CE contendo carboidrases ( $\alpha$-galactosidase, galactomananase, xilanase e $\beta$-glucanase), cujas características foram previamente descritas por CHAE et al. (2003), KIM \& BAKER (2003) e KIM et al. (2006). A adição do CE foi realizada na forma on top, ou seja, sem ocorrer reformulação das dietas, sendo utilizada uma concentração de $0,02 \%$, do CE, conforme recomendação da empresa fornecedora do produto.

O delineamento experimental foi em blocos completos casualizados, sendo bloqueado pela ordem de parto (OP). Cada bloco foi constituído por quatro fêmeas, onde os intervalos de OP foram divididos do seguinte modo: bloco 1: OP 1; bloco 2: OP 2; bloco 3: OP 3 a 6, com parição na mesma semana. As fêmeas foram selecionadas por ocasião da transferência para a maternidade, sendo a unidade experimental composta pela matriz suína e sua leitegada. Nas fêmeas, foram 
Tabela 1 - Ingredientes e análise bromatológica da dieta basal de lactação.

\begin{tabular}{lc}
\hline Ingredientes & Dieta basal $(\mathrm{kg})^{1}$ \\
\hline Milho grão & 59,50 \\
Farelo de soja 46\% & 30,00 \\
Óleo de soja & 3,00 \\
Açúcar & 3,50 \\
Fertimix L-40 ${ }^{\circledR 2}$ & 4,00 \\
Total & 100,0 \\
Composição analisada ${ }^{3}, \%$ & \\
Matéria seca & 89,51 \\
Proteína bruta & 19,92 \\
Extrato etéreo & 5,28 \\
Fibra bruta & 3,90 \\
Matéria mineral & 5,81 \\
\hline
\end{tabular}

${ }^{1}$ Valores calculados.

${ }^{2}$ Suplemento Vitamínico-mineral: quantidade por kg de produto: Vitamina A (UI) 300.000; Vitamina D3 (UI) 50.000; Vitamina E (mg) 667; Vitamina K3 (mg) 74; Vitamina B1 (mg) 25; Vitamina B2 (mg) 125; Vitamina B6 (mg) 62; Vitamina B12 ( $\mu$ g) 750; Vitamina C (mg) 12,5; Ácido Fólico (mg) 25; Ácido Nicotínico (mg) 625; Ác. Pantotênico (mg) 375; Biotina mg) 7,5; Colina (mg) 8.750; Fósforo (mín e máx. em g) 67 e 76; Cálcio (mín e máx em g) 208 e 237; Ferro (ppm) 2500; Sódio (g) 48; Mn (ppm) 2.002; Zinco (ppm) 2497; Cobre (ppm) 250; Iodo (ppm) 12,5; Selênio (ppm) 5,5; Cromo ( $\mu \mathrm{g})$ 5; Flúor (ppm) 720; Cobalto (ppm) 12,5; Antioxidante (mg) 250.

${ }_{3}$ Análises realizadas pelo Laboratório de Nutrição Animal da EMBRAPA Suínos e Aves, Concórdia, SC (2006).

avaliadas as seguintes variáveis: peso ao desmame (PDESM); variação do peso ao desmame (VPDESM); espessura de toucinho P2 três dias após o parto (P2PARTO), ao desmame (P2DESM) e à cobertura (P2COB); variação da espessura de toucinho $\mathrm{P} 2$ ao desmame (VP2DESM) e à cobertura (VP2COB); escore corporal três dias após o parto (ECPARTO), ao desmame (ECDESM) e à cobertura (ECCOB); consumo de ração (CRF) e composição do leite (teores de gordura, proteína bruta, lactose e matéria seca). Nos leitões, foram avaliados: consumo de ração (CRL), peso da leitegada ao nascer (PLNASC), peso da leitegada ao desmame (PLDESM) e peso médio do leitão ao desmame (PMLDESM).

Tabela 2 - Análise bromatológica da dieta pré-inicial dos leitões.

\begin{tabular}{ll}
\hline Variável & $\%$ \\
\hline Matéria seca & 87,0 \\
Proteína bruta & 20,0 \\
Extrato etéreo & 5,0 \\
Fibra bruta & 3,0 \\
Matéria mineral & 8,0 \\
\hline
\end{tabular}

A avaliação do escore corporal das fêmeas foi realizada através de avaliações visuais, utilizandose um índice entre 1 e 5, conforme LUDKE et al. (2001). As medidas de espessura de toucinho foram realizadas a 6,5cm da coluna vertebral, entre a penúltima e a última costela (P2), do lado direito do corpo do animal, com o auxílio de um aparelho de ultrassom portátil MTU-100 (EMBRAPA, CNPDIA, São Paulo, SP), utilizando-se metodologia adaptada de BISCEGLI \& FÁVERO (1996). Foram coletadas amostras de leite de 19 matrizes de cada tratamento (com e sem CE na dieta de lactação) para a avaliação da composição. As fêmeas foram ordenhadas manualmente, sendo escolhidos os pares de tetos peitorais após aplicação de $1 \mathrm{~mL}$ de ocitocina via endovenosa. As análises químicas foram realizadas pelo Laboratório de Qualidade do Leite da Companhia Integrada de Desenvolvimento Agrícola de Santa Catarina (CIDASC).

Com base nos resultados deste experimento, foi realizada uma análise econômica da suplementação do CE nas dietas das matrizes. Utilizouse o efeito principal observado pela suplementação enzimática, estimando-se o peso de abate dos animais a partir da variável peso do leitão ao desmame, através da função de Gompertz (WHITTEMORE \& GREEN, 2001).

Os dados foram submetidos à análise descritiva para verificação da normalidade, homogeneidade de variância e presença de outliers, utilizando-se o procedimento Guided Analysis (SAS, 2001), sendo os outliers retirados do conjunto de dados. Em seguida, esses dados foram submetidos ao procedimento GLM do SAS, considerando-se que os mesmos eram desbalanceados, sendo utilizados os efeitos de ordem de parto (bloco) e tratamentos no modelo principal, sendo corrigidos para variáveis de interesse através de análise de covariância. Foram utilizados como covariável os pesos dos leitões ao nascer e ao desmame.

\section{RESULTADOS E DISCUSSÃO}

Não houve interação significativa entre os fatores experimentais DL e DPI para nenhuma variável resposta. Não houve diferença $(\mathrm{P}>0,10)$ entre os tratamentos sobre PDESM e VPDESM (Tabela 3). Esses resultados não concordam com os encontrados por KIM (2002), que verificou redução significativa na variação de peso corporal de fêmeas primíparas que receberam carboidrases ( $\alpha$-1,6-galactosidase, $\beta-1,4$ mananase e ß-1,4-manosidase) na dieta, também durante a fase de lactação. Entretanto, o resultado obtido no presente experimento pode ser explicado, 
Tabela 3 - Efeito da suplementação de dietas de lactação e pré-inicial com um complexo enzimático contendo carboidrases sobre as variáveis de desempenho de fêmeas suínas lactantes e de suas leitegadas (média \pm erro padrão).

\begin{tabular}{|c|c|c|c|c|c|c|}
\hline \multirow{3}{*}{ Variáveis $^{1}$} & \multicolumn{2}{|c|}{-------------Dieta lactação------------- } & \multirow{3}{*}{$\mathrm{P}$} & \multicolumn{2}{|c|}{-----------Dieta pré-inicial------------ } & \multirow{3}{*}{$\mathrm{P}$} \\
\hline & & & & & & \\
\hline & Sem CE & Com CE & & Sem CE & Com CE & \\
\hline PDESM (kg) & $229,9 \pm 2,4$ & $228,5 \pm 2,4$ & 0,63 & $229,9 \pm 2,4$ & $228,5 \pm 2,4$ & 0,64 \\
\hline VPDESM (kg) & $32,8 \pm 1,5$ & $34,9 \pm 1,5$ & 0,26 & $34,4 \pm 1,5$ & $33,3 \pm 1,5$ & 0,56 \\
\hline P2PARTO (mm) & $19,6 \pm 0,1$ & $19,5 \pm 0,1$ & 0,50 & $19,6 \pm 0,1$ & $19,5 \pm 0,1$ & 0,56 \\
\hline P2DESM (mm) & $17,3 \pm 0,2$ & $17,3 \pm 0,2$ & 0,95 & $17,5 \pm 0,2$ & $17,2 \pm 0,2$ & 0,24 \\
\hline VP2DESM (mm) & $2,4 \pm 0,2$ & $2,2 \pm 0,2$ & 0,57 & $2,2 \pm 0,2$ & $2,4 \pm 0,2$ & 0,51 \\
\hline P2COB (mm) & $16,9 \pm 0,2$ & $16,8 \pm 0,2$ & 0,94 & $17,1 \pm 0,2$ & $16,6 \pm 0,2$ & 0,05 \\
\hline VP2COB (mm) & $-0,3 \pm 0,1$ & $-0,5 \pm 0,1$ & 0,29 & $-0,3 \pm 0,1$ & $-0,5 \pm 0,1$ & 0,15 \\
\hline ECPARTO & $3,3 \pm 0,1$ & $3,3 \pm 0,1$ & 0,53 & $3,2 \pm 0,1$ & $3,3 \pm 0,1$ & 0,46 \\
\hline ECDESM & $2,9 \pm 0,1$ & $2,8 \pm 0,1$ & 0,42 & $2,9 \pm 0,1$ & $2,9 \pm 0,1$ & 0,59 \\
\hline ECCOB & $2,9 \pm 0,1$ & $2,8 \pm 0,1$ & 0,62 & $2,8 \pm 0,1$ & $2,9 \pm 0,1$ & 0,68 \\
\hline PLNASC (kg) & $18,36 \pm 0,3$ & $19,29 \pm 0,3$ & 0,01 & $19,10 \pm 0,3$ & $18,55 \pm 0,3$ & 0,13 \\
\hline PLDESM (kg) & $72,9 \pm 0,7$ & $74,6 \pm 0,7$ & 0,06 & $74,1 \pm 0,7$ & $73,5 \pm 0,7$ & 0,51 \\
\hline PMLDESM (kg) & $6,32 \pm 0,063$ & $6,47 \pm 0,06$ & 0,07 & $6,42 \pm 0,06$ & $6,37 \pm 0,06$ & 0,49 \\
\hline CRF (kg) & $107,0 \pm 1,3$ & $107,3 \pm 1,3$ & 0,88 & $106,6 \pm 1,3$ & $107,7 \pm 1,3$ & 0,51 \\
\hline CRL (kg) & $0,41 \pm 0,02$ & $0,40 \pm 0,02$ & 0,69 & $0,40 \pm 0,02$ & $0,41 \pm 0,02$ & 0,38 \\
\hline
\end{tabular}

${ }^{1}$ PDESM: peso da fêmea ao desmame; VPDESM: variação de peso da fêmea ao desmame; P2PARTO: espessura de toucinho da fêmea três dias após o parto; P2DESM: espessura de toucinho da fêmea ao desmame; P2COB: espessura de toucinho da fêmea à cobertura; VP2COB: variação de espessura de toucinho à cobertura; ECPARTO: escore corporal da fêmea três dias após o parto; ECDESM: escore corporal da fêmea três dias após o parto; ECCOB: escore corporal da fêmea à cobertura; PLNASC: peso da leitegada ao nascer; PLDESM: peso da leitegada ao desmame; PMLDESM: peso médio do leitão ao desmame; CRF: consumo de ração da fêmea; CRL: consumo de ração da leitegada.

provavelmente, devido a pesagem dos leitões ter sido realizada após a equalização das leitegadas, não sendo possível assim calcular a variação real de peso das fêmeas.

Houve efeito significativo da dieta préinicial $(\mathrm{P}=0,05)$ sobre a $\mathrm{P} 2 \mathrm{COB}$, sendo verificada uma espessura de toucinho menor quando a dieta foi suplementada com CE. Quando foi analisada esta variável em relação à VP2COB, não houve diferença significativa entre os tratamentos ( $\mathrm{P}>0,10$, Tabela 3 ), demonstrando a inconsistência desse efeito. Esses dados corroboram os encontrados por LINDEMANN et al. (2006), que, ao adicionarem as enzimas ß-glucanase e ß-xilanase na dieta de suínos em crescimento, em terminação, não observaram diferença significativa na espessura de toucinho.

Em relação às variáveis de escores corporais das fêmeas, não foi observado efeito significativo entre os tratamentos ( $\mathrm{P}>0,10$, Tabela 3$)$. Os resultados acompanharam o comportamento das fêmeas quanto à variação de peso, bem como quanto à espessura de toucinho, demonstrando que a adição do CE na dieta não foi capaz de reduzir as perdas corporais que ocorreram durante a fase de lactação. O resultado observado pode ser explicado, possivelmente, pela prioridade da fêmea suína em utilizar a energia consumida para a produção de leite, não restando assim energia para ser armazenada na forma de tecido adiposo.

Foi observado que o PLNASC diferiu entre os tratamentos ( $\mathrm{P}=0,01$, Tabela 3$)$, o que aconteceu aleatoriamente, uma vez que os tratamentos ainda não haviam sido implementados. Entretanto, essa diferença encontrada no peso dos leitões foi importante para se ajustar o peso ao desmame para mesmo peso ao nascer. O PLDESM e o PMLDESM foram significativamente maiores ( $\mathrm{P}=0,06, \mathrm{P}=0,07$, respectivamente, Tabela 3 ) quando a DL foi suplementada com CE, quando comparados com os leitões das fêmeas que receberam ração sem CE. Assim, os leitões das fêmeas que receberam CE na DL apresentaram aumento de $1,7 \mathrm{~kg}$ por leitegada e de 0,14kg por leitão. Esses resultados não concordam com os obtidos por KIM (2002), que não observou diferença significativa no peso ao desmame de leitões de fêmeas que receberam rações de lactação contendo um CE de carboidrases ( $\alpha-1,6$ galactosidase, ß-1,4-mananase e ß-1,4-manosidase).

O aumento do PLDESM e do PMLDESM com a suplementação da DL com CE observado neste trabalho pode ter ocorrido devido à maior digestibilidade e retenção de nutrientes, pois a suplementação da dieta de fêmeas lactantes com a 
enzima xilanase resultou no aumento da digestibilidade da energia bruta (DE SOUZA, 2003). Assim, pode ter ocorrido aumento na produção de leite pela maior liberação de energia para as fêmeas e, consequentemente, pelo maior peso da progênie ao desmame. Outros autores demonstram que a adição de enzimas carboidrases nas dietas de suínos aumenta a digestibilidade dos nutrientes, promovendo melhor aproveitamento das rações consumidas, melhorando assim o desempenho dos animais (CHAE et al., 2003; KIM \& BAKER, 2003; KIM et al., 2006).

Não foram observadas diferenças significativas entre os tratamentos sobre o CRF e o CRL ( $\mathrm{P}>0,10$, Tabela 3). Assim, observou-se que o consumo de dieta pelos leitões não contribuiu para o aumento no PLDESM e no PMLDESM quando a DPI foi suplementada com CE. Os resultados observados para o consumo de ração dos leitões corroboram os encontrados por KIM et al. (2003) e PASCOAL et al. (2006), que não observaram diferença no consumo de ração de leitões desmamados aos 21 dias, que consumiram rações à base de milho e farelo de soja, contendo um complexo enzimático semelhante ao utilizado neste experimento. KIM et al. (2003) e KIM \& BAKER (2003) observaram ainda que a adição de carboidrases em dietas pré-iniciais contendo baixos níveis (20 a 25\%) de farelo de soja não melhorou o desempenho de leitões; no entanto, quando foi utilizado um nível de 32,4\% de farelo de soja, houve melhora na eficiência alimentar e na digestibilidade de energia e aminoácidos, aumentando o ganho de peso. Assim, o resultado obtido no presente experimento pode ter ocorrido pela baixa concentração do farelo de soja utilizado na dieta pré-inicial dos leitões lactentes.

Apesar de não ter sido observada diferença no CRL, o aumento do PLDESM observado neste experimento pode estar associado a uma maior capacidade de absorção dos nutrientes provenientes do leite da mãe, como também à suplementação enzimática da dieta pré-inicial dos leitões, uma vez que KIM et al. (2003) e PASCOAL et al. (2008) verificaram um aumento das vilosidades intestinais de leitões desmamados aos 21 dias com a adição de carboidrases na dieta.

Em relação à variável CRF, os resultados obtidos concordam com KIM (2002), que não observou diferença significativa no consumo de fêmeas lactantes que receberam dietas contendo CE semelhante ao utilizado neste experimento. De modo semelhante, KIM et al. (2006) não encontraram diferença significativa no consumo de ração de suínos em crescimento e terminação que receberam CE de carboidrases ( $\alpha$-1,6galactosidase, ß-1,4-mananase e ß-1,4-manosidase) na dieta. Os resultados obtidos no presente experimento demonstram que, durante a fase de lactação, a suplementação da dieta com CE de carboidrases não estimula ou deprime o consumo de alimento de fêmeas lactantes.

Não foram encontradas diferenças significativas na composição do leite em relação aos teores de matéria seca, gordura, proteína bruta e lactose das fêmeas que receberam dietas sem e com CE (18,73 vs $18,44 \%$; 8,62 vs $8,15 \%$; 4,45 vs $4,31 \%$; 5,08 vs $5,15 \%$, respectivamente, $\mathrm{P}>0,10)$. Assim, o aumento do PLDESM e do PMLDESM não pode ser associado ao aumento dos nutrientes do leite das fêmeas que receberam DL com CE.

A análise econômica demonstrou que houve um ganho líquido de $\mathrm{R} \$ 0,53$ por suíno ao abate para os animais que foram desmamados de porcas que receberam CE na dieta, o que correspondeu a 2,27kg a mais de peso vivo para cada suíno produzido, quando esses animais chegaram ao peso de abate.

\section{CONCLUSÃO}

Fêmeas suínas em lactação alimentadas com dietas suplementadas com um complexo enzimático contendo carboidrases produzem leitegadas mais pesadas ao desmame.

\section{AGRADECIMENTO}

Ao Comércio e Indústria UNIQUIMICA Ltda, pelo apoio técnico e financeiro e pelo fornecimento do complexo enzimático utilizado (ENDOPOWER Beta ${ }^{\circledR}$ ); à Granja JaboráCOPERIO, pelo apoio na execução do experimento e das instalações; e ao Conselho Nacional de Desenvolvimento Científico e Tecnológico ( $\mathrm{CNPq}$ ), pela bolsa de mestrado concedida ao primeiro autor.

\section{REFERÊNCIAS}

BISCEGLI, C.I.; FÁVERO, J.A. Recomendação sobre o uso de ultra-som na medida da espessura de toucinho em suínos vivos. São Carlos, SP: EMBRAPA-CNPDIA, 1996. 4p. (Comunicado Técnico).

CHAE, B. et al. Effects of phytase and carbohydrases supplementation to diet with a partial replacement of soybean meal with rapeseed meal and cottonseed meal on growth performance and nutrient digestibility of growing pigs. AsianAustralasian Journal of Animal Sciences, v.16, p.13391347, 2003.

DE SOUZA, A.L.P. Assessment of dietary enzyme supplementation on ileal and total tract digestibilities in gestating and lactating swine. 2003. 165f. Thesis (Ph.D. in Animal Sciences) University of Kentucky, Lexington, KY, USA. 
KIM, S.W. Effect of alpha-1,6 -galactosidase, beta-1,4mannanase, and beta- 1,4- mannosidase on lactation performance in primiparous sows. Journal of Animal Science, v.80, Suppl.2, p.58-59, 2002. (Abstract).

KIM, S.W.; BAKER, D.H. Use of enzymes supplements in pig diets based on soyabean meal. Pig News and Information, v.24, p.91-95, 2003.

KIM, S.W. et al. Use of carbohydrases in corn- soybean mealbased nursery diets. Journal of Animal Science, v.81, p.2496-2504, 2003.

KIM, S.W. et al. Use of carbohydrases in corn-soybean meal based grower- finisher pig diets. Animal Research, v.55, p.563-578, 2006. Disponível em: <http:// a $n$ i m r e s. e d p s c i e n c e s. o r g/ index.php?option=article \&access $=$ doi \&doi=10.1051/ animres:2006039>. Acesso em: 14 dez. 2008. doi: 10.1051/ animres:2006039.

LINDEMANN, M.D. et al. Evaluation of a carbohydrase combination on performance in growing-finishing pigs. Journal of Animal Science, v.79, Suppl.1, p.471, 2006. (Abstract).

LUDKE, J.V. et al. Alimentação das fêmeas suínas segundo sua condição corporal. 2000. Acesso em: 12 mar. 2008. Online. Disponível na internet http://www.cnpsa.embrapa.br.

PASCOAL, L.A.F. et al. Desempenho de leitões submetidos a diferentes níveis de complexo enzimático. Archivos em Zootecnia, v.55, n.209, p.93-96, 2006
PASCOAL, L.A.F. et al. Complexo enzimático em dietas simples sobre os parâmetros séricos e a morfologia intestinal de leitões. Revista Brasileira de Saúde e Produção Animal, n.1, v.9, p.117-129, 2008.

PENZ JUNIOR, A.M. Enzimas em rações para aves e suínos. In: REUNIÃO ANUAL DA SOCIEDADE BRASILEIRA DE ZOOTECNIA, 35., 1998, Botucatu. Anais... Botucatu: SBZ, 1998. p.165-178.

SAS INSTITUTE. SAS/STAT User's guide. Version 8.2. Cary, NC, 2001. 943p.

SHEPPY, C. The current feed enzyme market and likely trends. In: BEDFORD, M.R.; PARTRIDGE, G.G. Enzymes in farm animal nutrition. Marlborough: CAB International, 2001. p.1-10.

XAVIER, E.G. Effects of phytase in diets containing lowphytate corn and soybean meal on performance, bone traits, and phosphorus excretion of pigs and chicks. 2003. 273f. Thesis (Ph. D. in Animal Sciences) - University of Kentucky, Lexington, KY, USA.

XAVIER, E.G. et al. Production economics and pig health: use of Allzyme ${ }^{\mathrm{TM}}$ Vegpro in feed formulation. In: NUTRITIONAL BIOTECHNOLOGY IN THE FEED AND FOOD INDUSTRIES, 2005, Lexington, UK. Proceedings of Alltech's 21 ${ }^{\text {st }}$ Annual Symposium. Nottingham, England: Nottingham University, 2005. p.221-228.

WHITTEMORE, C.T.; GREEN, D.M. Growth of young weaned pig. In: VARLEY, M.A.; WISEMAN, J. The weaner pig nutrition management. Nottingham: CAB, 2001. p.1-15. 